\title{
BUNKASAI, KAJIAN SEMIOTIKA BUDAYA KONTEMPORER DARI PENGARUH FILM JEPANG
}

\author{
Triadi Sya'Dian \\ Prodi Televsi dan Film Universitas Potensi Utama \\ triadisyadian@gmail.com
}

\begin{abstract}
ABSTRAK
Bunkasai adalah acara bertema jejepangan yang diselenggarakan oleh Fakultas Ilmu Budaya Universitas Sumatera Utara, Medan. Ini merupakan event tahunan bekerjasama dengan konsulat Jendral Jepang di Medan dan bersifat terbuka untuk umum. Bunkasai merupakan salah satu bentuk dampak dari perkembangan budaya popular Film jepang. Terdapat berbagai kegiatan-kegiatan yang menyuguhkan kebudayaan jepang pada acara tersebut. Salah satunya adalah kegiatan perlombaan Costum Player atau biasa dikenal Cosplay yang mampu menarik masyarakat dalam kota maupun luar kota. Penelitian ini bersifat kualitatif menggunakan pendekatan semiotika. Metode pengumpulan data dengan studi pustaka, observasi, dan wawancara. Hasil penelitian menjelaskan adanya pengaruh kuat dari Film jepang terhadap event Bunkasai dimana lebih banyak menghadirkan budaya popular jepang di banding budaya asli jepang.
\end{abstract}

Kata Kunci : Semiotika, Bunkasai, Budaya Populer,

\begin{abstract}
Bunkasai is a workshop-themed event organized by the Faculty of Cultural Sciences, University of North Sumatra, Medan. This is an annual event in collaboration with the Japanese Consulate General in Medan and is open to the public. Bunkasai is one form of the impact of the development of Japanese film popular culture. There were various activities that presented Japanese culture at the event. One of them is the activity of the Costum Player or commonly known as Cosplay which is able to attract people in the city and outside the city. This research is qualitative using a semiotic approach. Methods of collecting data with literature studies, observations, and interviews. The results of the study explain the strong influence of Japanese films on the Bunkasai event where more popular Japanese culture is compared to native Japanese culture.
\end{abstract}

Keyword $\quad$ : Semiotic, Bunkassai, Popular culture

\section{PENDAHULUAN}

\subsection{Latar belakang}

Budaya dalam cultural studies lebih didefinisikan secara politis ketimbang estetis. Objek kajian dalam Cultural studies bukanlah budaya yang didefinisikan dalam pengertian sempit yaitu sebagai objek keadiluhungan estetis ('seni tinggi'); juga bukan budaya yang didefinisikan dalam pengertian yang sama-sama sempit, yaitu sebagai sebuah proses perkembangan estetik, intelektual, dan spiritual; melainkan budaya yang dipahami sebagai 
teks dan praktik hidup sehari-hari.(John storey, 2008: 2) Inilah definisi budaya menurut John Storey yang biasa melibatkan budaya pop yang bergerak melampaui eksklusivitas sosial dan sempitnya definisi budaya ini.

Isu-isu seni dan pengaruh kebudayaan luar sangat mudah ditemui dan bermunculan dimana-mana. Hal ini disebabkan pengaruh media massa yang terus dikonsumsi oleh generasi muda melalui televisi, gadget, internet dan sebagainya. Pergaulan dan paradigma atau pola pikir pun menjadi taruhannya. Seperti halnya budaya dari Jepang. Jepang memiliki banyak budaya popular yang diakui, dinikmati, disebarluaskan ke mancanegara. Budaya popular Jepang seperti fashion, acara televisi, manga, anime, permainan computer, dan music, serta jalan hidup mayoritas masyarakat Jepang secara umum telah memasuki kawasan Asia secara mendalam. Berawal dari idola dan animasi, budaya Jepang menciptakan banyak komunitas penggemar di kawasan Asia. Film menjadi salah satu faktor pengaruh budaya Jepang yang disebar melalui media massa di Indonesia. Film-film jepang ini tidak tersebar melalui stasiun televisi swasta Indonesia, melainkan melalui situs-situs internet. Film Jepang seperti anime sangat diminati semua kalangan di Indonesia.

Anime merupakan istilah yang disingkat untuk menyebutkan film animasi jepang. Kata tersebut berasal dari kata animation yang dalam pelafalan bahasa jepang menjadi animeshon. Anime telah menjadi komoditas internasional, semakin menarik perhatian banyak akademisi maupun dari berbagai bidang maupun Negara. MacWilliams (2011:5) menyebut dua urgensi penelitian mengenai anime. Pertama, anime merupakan bagian kunci dalam budaya visual popular Jepang. Di tengah besarnya peran media massa (masu-komi) dalam masyarakat Jepang, anime dan juga manga (komik Jepang) menjadi bagian yang tak terpisahkan dalam kehidupan masyarakat Jepang yang sangat visual. Kedua, anime berperan penting dalam pembentukan mediascape global, baik cetak maupun elektronik. McWilliams (2011: 3) menyebut Jepang sebagai "image world" dimana media massa Jepang yang sangat visual dikonsumsi oleh tidak hanya masyatakat Jepang sendiri, namun juga kini oleh masyarakat global.

Anime mulai dikenal di Indonesia dengan sebutan berbeda yaitu kartun pada tahun 1990an. Masuknya film-film kartun yang ditayangkan di televisi lokal dan bahkan namanya masih dikenal hingga saat ini seperti film Astro-Boy, Doraemon, Dragon Ball, Gundam, perlahan mulai mendongkrak popularitas anime. Di penghujung tahun 2000 anime mulai meroket drastis dengan hadirnya variasi genre dari anime. Anime bergenre action dan fantasy sangat diminati dan sangat fresh pada masa itu, seperti Naruto, One Piece, Samurai X, Inuyasha, Detective Conan, dan banyak lagi.

Pengaruh perkembangan anime sudah menjadi budaya popular di Indonesia, khususnya kota-kota besar yang dimana para penggemarnya bukan hanya dari kalangan anak-anak tetapi juga berasal dari kalangan remaja dan dewasa. Budaya popular merupakan produk masyarakat industrial dimana kegiatan pemaknaan dan hasil kebudayaan ditampilkan dalam jumlah besar dan kerap kali dengan bantuan teknologi produksi, distribusi, serta penggandaan massal, sehingga mudah dijangkau oleh masyarakat (Heryanto, 2012: 9). Otaku merupakan salah satu sebutan bagi penggiat kebudayaan popular ini. Selain mengikuti perkembangan anime seperti mengoleksi series anime maupun action figure, mereka juga mulai berkumpul membentuk komunitas untuk sekedar berbagi (sharing) hingga mengadakan event-event budaya jepang.

Antusiasme masyarakat terhadap anime baik penggemar dalam bentuk komunitas maupun bukan penggemar terasa sangat tinggi. Fenomena tersebut dapat dilihat dari maraknya event-event yang bertajuk jejepangan diadakan di kota-kota besar Indonesia. Acara-acara ini 
selalu diadakan tahunan dan disambut positif serta dihadiri banyak massa dari berbagai kalangan. Sebagai salah satu contoh ialah acara Bunkasai USU 2018. Bunkasai USU 2018 adalah acara yang diadakan oleh Fakultas Ilmu Budaya Universitas Sumatera Utara (AotakeHinode) melalui program studi Sastra dan Bahasa Jepang bekerja sama dengan Konsulat Jendral Jepang di Medan (www.usu.ac.id/id/1763-fib-usu-gelar-bunkasai-2018.html). Bunkasai (文化 祭) merupakan sebuah acara tahunan yang diselenggarakan oleh sebagian besar sekolah hingga universitas di Jepang. Event ini kemudian diadaptasi di berbagai daerah di Indonesia. Bunkasai di Indonesia umumnya berpadu antara budaya Indonesia dan Jepang. Penelitian "Bunkasai, Kajian Semiotika Budaya Kontemporer dari pengaruh Film Jepang" menggunakan metode penelitian kualitatif. Menurut Bogdan dan Taylor berpendapat bahwa metodologi penelitian kualitatif sebagai prosedur penelitian yang menghasilkan data deskriptif berupa kata-kata tertulis atau lisan dari orang-orang dan periaku yang dapat diamati (Moleong, 2001: 3). Dengan demikian sumber-sumber data dapat diperoleh dari wawancara, sumber tertulis, foto, audio dan visual.

Data penelitian dikumpulkan dengan teknik kualitatif. Data kualitatif berupa observasi dan wawancara. Data kualitatif atau statistik dianalisis melalui metode konstan komparatif. Semua data mengenai Film Nagabonar yang didapatkan berupa rekaman audio visual, wawancara, catatan lapangan, maupun kepustakaan diklarifikasi sesuai dengan apa yang dibutuhkan. Kemudian data-data tersebut dianalisa berdasarkan teori yang digunakan. Dari hasil analisa tersebut didapatlah kesimpulan yang menjawab segala pertanyaan yang ada pada rumusan masalah.

\subsection{Teori Semiotika}

Perkembangan semiotika film sebagai sebuah metode mendapat pengaruh dari tiga orang yatu; Christian Metz, Juri Lotman dan Rolan Barthes. Pertanyaan utama adalah mengaplikasikan semiotika sebagai metode interpretasi film adalah bagaimana film tersebut mempunyai signifikansinya (how does the film signify?) dalam pengertian sebagai media penandaan. Karena film berbicara melalui tanda-tanda konvensional atau melalui bahasa film (Danesi, 2002: 122-128). Dalam opininya, lebih tepat dikatakan bahwa film sebagai suatu teks sinematik telah memperluas kategori-kategori yang dibuat oleh bahasa dengan menggabungkan dialog, usik, adegan dan peran dalam suatu caranya yang kohesif. Film lebih tepat sebagai suatu media penggabungan yang dibuat oleh penanda herbal dan non verbal.

Rose (2007: 87, juga Kress, et al, 2006) berpendapat bahwa ideologi juga mempunyai peranan penting untuk memunculka signifikasi tanda-tanda. Rose, mendasarkan pandangannya pada pendapat Williamson (1978) dan Barthes (1973), menegaskan pemisahan struktural metafora tanda yang mengarah pada metonimic, yaitu tanda yang berasosiasi dengan suatu dan kemudian mempressentasikan sesuatu, dan sinekdot, yaitu tanda spesial yang dapat mempresentasikan keseluruhan makna atau sebaliknya.

Menurut Ferdinand De Saussure (1857-1913), semiotik dibagi menjadi dua bagian (dikotomi) yaitu penanda (signifier) dan pertanda (signified). Penanda dilihat sebagai bentuk/wujud fisik dapat dikenal melalui wujud karya arsitektur, sedang pertanda dilihat sebagai makna yang terungkap melalui konsep, fungsi dan/atau nilai-nlai yang terkandung didalam karya arsitektur. Eksistensi semiotika Saussure adalah relasi antara penanda dan petanda berdasarkan konvensi, biasa disebut dengan signifikasi. Semiotika signifikasi adalah sistem tanda yang mempelajari relasi elemen tanda dalam sebuah sistem berdasarkan aturan atau 
konvensi tertentu. Kesepakatan sosial diperlukan untuk dapat memaknai tanda tersebut. Menurut Saussure, tanda terdiri dari: Bunyi-bunyian dan gambar, disebut signifier atau penanda, dan konsep-konsep dari bunyi-bunyian dan gambar, disebut signified.

\section{STUDI LITERATUR} berikut :

Beberapa referensi penulisan pustaka yang dirujuk dalam tulisan ini adalah sebagai

Analisis Simbolik Pada Upacara Pernikahan Adat Pakpak (Kajian Semiotik) oleh Fitri Sari Berampu, Dr. Abdurahman Adisaputera, M.Hum. Penelitian ini bertujuan untuk menganalisis bentuk simbolik yang terdapat pada upacara pernikahan adat Pakpak, makna denotasi dan makna konotasi bentuk simbolik yang terdapat pada upacara pernikahan Adat Pakpak dan mitos bentuk simbolik yang terdapat pada upacara pernikahan adat Pakpak. Penelitian ini menggunakan teori semiotika Roland Barthes. Metode yang digunakan dalam penelitian ini adalah metode penelitian kualitatif deskriptif. Instrumen penelitian adalah peneliti sendiri. Teknik pengumpulan data yang dipakai adalah teknik simak dan teknik catat berupa rekaman. Teknik ini digunakan agar memperoleh data secara detail dan menyeluruh.

Data dari penelitian ini adalah tuturan. Dari hasil penelitian, terdapat 17 bentuk simbolik yang digunakan pada upacara pernikahan adat Pakpak. Bentuk simbolik itu seperti, 1) Mberas Mpihir (beras), 2) Gatap (sirih), 3) Pinggan Pasu (piring Putih), 4) Emas, 5) Kepeng (uang), 6) Kembal , 7) Baka SIlampis, 8) Blagen (Tikar) 9)Oles, 10) Luah (buah tangan), 11) ayam, 12) bagian kepala hewan ternak, , 13) Bagian hati hewan ternak, 14) Bagian tulang hewna ternak, 15) Bagian dada hewan ternak, 16) bagian ekor hewan ternak 17) ikan Simundur mundur. Dari bentuk simbolik tersebut memiliki makna denotasi, makna konotasi dan mitos. Secara umum, pemberian bentuk simbolik tersebut pada upacara adat Pakpak merupakan simbol penghormatan terhadap anggota keluarga dan simbol telah melaksanakan suatu upacara adat yang besar.

Hasil penelitian berupa makna mitos, makna terdalam yang biasanya bersifat konvensional menggambarkan bahwa masyarakat Pakpak pada upacara pernikahan (Membayo) , masyarakat yang menghormati sistem kekeluargaan, mengutamakan permusyawarahan, mengharapkan berkat dari Tuhan, saling mendoakan, tidak lupa akan sejarah kekeluargaan, dan menggunakan simbol perlengkapan pernikahan dari pekerjaan dan hasil ternak yang dilakukan oleh masyarakat Pakpak. Persamaan dari penelitian ini terdapat pada kajian Simbolik terhadap suatu acara pada model masyarakat tertentu.

Kajian Makna Simbolik Pada Wayang Bawor Oleh Juli Prasetya. Penelitian ini bertujuan untuk mengetahui apa saja makna simbolik yang terkandung pada wayang Bawor. Bawor merupakan tokoh wayang yang digunakan sebagai ikon / simbol wong Banyumas sehingga penulis tertarik untuk mengkaji lebih dalam mengenai hal-hal yang berkaitan dengan kajian makna simbolik pada wayang Bawor. Dalam penelitian ini penulis menggunakan teori analisis semiotika Charles Sanders Peirce yakni melalui proses semiosis yang terdiri dari tiga tahapan penandaan. Mulai dari representamen (tanda), object (sesuatu yang lain) dan interpretant (proses penafsiran). Kemudian membagi jenis tanda kepada acuannya menjadi tiga jenis yakni ikon, indeks dan simbol. Artinya cara menggunakan analisis semiotika Peirce adalah dengan 
menentukan tanda ikon, indeks dan simbol kemudian dikupas dan ditafsiri sesuai dengan kapasitas penafsir.

Hasil dari penelitian ini adalah dalam tokoh Bawor ternyata terdapat banyak makna simbolik dalam tubuh Bawor maupun karakternya serta memiliki nilai-nilai yang luhur, seperti jujur, cerdas, egaliter dan lain-lain. Namun Bawor yang telah dijadikan simbol dan ikon oleh manusia Banyumas ternyata tidak serta merta menjadikan manusia Banyumas menjadi cerminan Bawor itu sendiri. Makna yang terkandung kemudian penulis jelaskan melalui analisis Semiotika Peirce dengan beberapa jenis tanda, mulai dari indeks, ikon dan Simbol yang terdapat pada wayang Bawor, melalui makna filosofis tubuhnya maupun karakternya yang merepresentasikan masyarakat Banyumas.

Dengan menganalisis makna simbolik pada wayang Bawor dengan menggunakan analisis semiotika Charles Sanders Peirce, ada beberapa karakter Bawor yang sudah terimplementasikan dengan baik dalam sebagian masyarakat Banyumas (pedesaan). Seperti Cablaka, Jujur dan Egaliter. Makna dan simbol pada wayang Bawor memiliki nilai kemanusiaan yang luhur, dan Islami. Secara keseluruhan Bawor yang dijadikan sebagai simbol manusia Banyumas perlu disikapi dengan arif dan bijaksana. Salah satu simbolik yang terkandung dalam tubuh dan karakter Bawor melalui jenis tanda indeks antara lain yakni: rambut kuncir lima helai yang menghadap ke atas dalam konsepsi Islam disebut rukun Islam, rambut menghadap ke atas bisa juga dimaknai sebagai hubungan vertikal antara mahluk dan Tuhannya. Persamaan terhadap penelitian ini terdapat pada kajian semiotika simbolik sebuah tokoh yang terdapat pada sebuah pertunjukan.

\section{PEMBAHASAN}

\section{Awal mula Bunkassai dan Perkembangannya di Medan}

Festival budaya dalam bahasa inggris Cultural Festival dalam bahasa Jepang Bunkassai merupakan salah satu festival yang cukup terkenal. Bunkasai diadakan mulai dari sekolah dasar hingga perguruan tinggi. Untuk waktu penyelenggaraan, umumnya disesuaikan dengan hari jadi sekolah yang bersangkutan. Bunkasai diadakan dengan tujuan agar para siswa dapat menampilkan kemampuan mereka dalam berkreatifitas. Dalam acara bunkasai, para siswa bebas menentukan apa yang akan mereka tampilkan atau jual, dan yang sering ada dalam bunkasai antara lain Rumah Hantu, Rumah Peramal, Cafe Maid, dan berbagai macam kegiatan lainnya.

Awalnya festival budaya, atau bunkasai ditujukan sebagai media pembelajaran, namun lama-kelamaan berubah menjadi tempat rekreasi. Meskipun begitu, tujuan utama tidak hilang begitu saja, karena para siswa mendapatkan pembelajaran ketika membuat suatu kegiatan bersama teman-teman sekelasnya. Sebelumnya bunkasai tidak terlalu terkenal, terutama bagi orang yang ada diluar jepang, namun semenjak anime dan manga banyak yang memasukkan festival-festival, termasuk bunkasai, kegiatan ini sudah mulai dikenal oleh orang luar, dan salah satunya di kota Medan, khususnya Universitas Sumatera Utara (USU) dengan acara tahunannya yang dipelopori oleh Fakultas Ilmu Budaya.

Ide penyelenggaraan Bunkasai oleh Fakultas Ilmu Budaya Universitas Sumatera Utara pertama kali sekitar tahun 2009 silam dengan persiapan yang matang dan dibantu oleh Konsulat Jenderal Jepang di Medan itu sendiri, maka terselenggaralah festival Bunkasai I.( 
http://www.cakapmedan.com/artikel.php?artikel=20). Tahun 2018 menjadi tahun yang ke10 kalinya acara festival ini diadakan. Bunkasai kembali dihadirkan tahun ini dengan mengusung tema 'Yushuuna Tanjoubi', yang berarti 'ulang tahun yang baik'. Acara ini juga sekaligus merayakan ulang tahun hubungan diplomasi Indonesia-Jepang yang ke-60. Bunkasai di tahun ke-10 ini diselenggarakan selama tiga hari (04-06/05) dengan maskotnya yakni Yuki (seorang samurai laki-laki asal Jepang yang pemberani dan pantang menyerah) dan Nana (seorang wanita cantik asal Indonesia yang memegang panah).

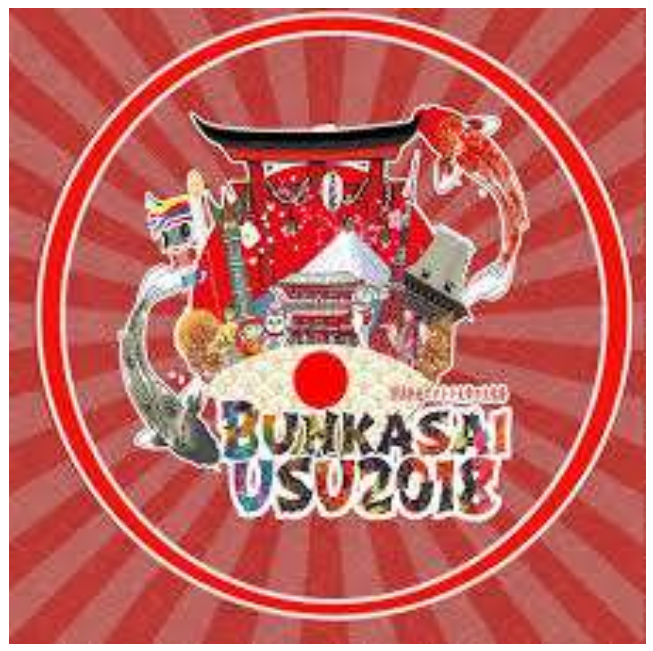

\section{Gambar 1. Poster Bunkasai 2018 USU}

(sumber : images.google.com)

Acara yang didukung penuh oleh konsulat Jepang di Medan ini sengaja mendatangkan artis langsung dari Jepang, yaitu : Egami Sakito (cosplayer asal Singapura) dan Hiroaki Kato (penyanyi asal Jepang) (http://www.mediapijar.com/2018/05/kemeriahan-festival-budayajepang-pada-bunkasai-usu-2018/). Seperti biasa, acara ini digelar selama tiga hari. Acara lain yang disajikan cenderung tidak berbeda dari tahun sebelumnya tapi selalu dinanti oleh seluruh hadirin maupun peserta yang hadir seperti cosplay, yukata, lomba menggambar manga, bazar, tarian-tarian jepang dan lain sebagainya. Dari tahun ke tahun peminat akan kebudayaan ini terus bertambah seiiring perkembangan jaman, terutama pada kalangan pelajar di kota-kota besar khususnya Medan. Masyarakat yang hadir pun beragam mulai dari siswa SMP sampai mahasiswa yang ada di kota Medan, penikmat budaya Jepang maupun tidak.

\section{Bunkasai interpretasi film Animasi Jepang (Anime)}

Otaku secara bahasa berarti seseorang yang terobsesi dengan satu bidang khusus, dalam hal ini bidang tersebut berasal dari budaya Jepang. Otaku sendiri bermacam-macam jenisnya, dari Otaku Robot, Otaku Kereta Api, Otaku Komputer dan sebagainya. Namun di Indonesia, ketika seseorang mengatakan kata Otaku maka Otaku yang dimaksud adalah Otaku Anime, itu karna Otaku Anime lebih populer dibandingkan Otaku lainnya. Jika dijabarkan secara semestinya, Otaku seringkali dimaknai negatif sebab itu di Jepang banyak orang yang merasa malu disebut Otaku. Karna Otaku berarti seorang yang saking fanatiknya terhadap anime hingga mengabaikan kehidupan di dunia nyata. Namun, di Indonesia istilah Otaku mengalami pergeseran makna dari yang fanatik terhadap Anime menjadi yang sekedar hobby nonton Anime 
tanpa harus mengabaikan kehidupan di dunia nyata. Jadi jika kita mendengar kata Otaku di Indonesia maka sebenarnya yang dimaksud adalah Anime Lovers, yaitu pecinta anime yang tetap memperhatikan hubungan di dunia nyata.

Di Indonesia, Otaku membentuk kelompok sosial di dunia nyata maupun di dunia maya. Untuk masuk ke dalam dunia Otaku keberadaan internet sangat diperlukan, karna Otaku adalah hobby yang sulit ditekuni tanpa keberadaan internet. Seseorang yang hanya tau Anime yang diputar di Televisi swasta saja belum bisa dikatakan sebagai Otaku. Para Otaku setidaknya harus mengetahui judul-judul Anime yang populer di kalangan Komunitas Otaku sehingga dia bisa ikut dalam perbincangan Komunitas Otaku. Dan judul-judul populer tersebut hanya bisa didapatkan melalui internet. Pemasaran Anime dalam bentuk DVD masih sangat jarang ditemui di Indonesia.

Anime yang dinikmati para Otaku tidak di "dubbing” ke bahasa Indonesia dan hanya menggunakan subtitle sebagai alat bantu bahasa, maka para Otaku menjadi cukup familier dengan bahasa Jepang. Beberapa bahasa Jepang pun menjadi bahasa gaulnya para Otaku. Sebab itulah kita bisa menemukan para Otaku menggunakan beberapa kosakata Jepang dalam perbincangannnya dengan sesama Otaku. Seperti menyebutan "kawai" yang berarti manis, "moe" yang berarti imut, "kakkoi" yang berarti keren, dan istilah-istilah lain yang sering terdengar dari Anime yang ditonton sama halnya seperti kata "Bunkasai".

Komunitas Otaku tersebar diberbagai penjuru termasuk kota Medan dimana komunitas ini cukup terorganisir. Seringkali komunitas Otaku membuat pertemuan rutin dan mengadakan banyak kegiatan, dari sekedar diskusi Anime hingga pengadaan kompetisi sebagai ajang mengasah kreatifitas. Meski sering dipandang sebelah mata, banyak Otaku yang memiliki kreatifitas lebih dibanding umumnya masyarakat. Kreatifitas tersebut pun bentuknya beragam. Banyak Otaku terobsesi membentuk Band musik karna termotivasi dengan Anime yang ditontonnya, banyak pula Otaku mengasah kemampuan menggambarnya karna kecintaaannya pada tokoh Anime idolanya, juga kreatifitas dalam desain kostum untuk para cosplayer atau kemampuan berbahasa Jepang bagi para translator atau dalam menulis artikel sebagai sarana informasi para Otaku dan banyak kreatifitas lain yang dikembangkan.

Kreatifitas-kreatifitas ini yang sebenarnya cukup membuat penasaran serta rasa ingin tau masyarakat untuk menyaksikan acara Bunkasai. Seperti halnya dengan Ika mahasiswi asal UMSU, "Saya tidak suka jejepangan, tapi saya datang kesini karena ada cosplay-cosplay nya yang menarik, banyak makanan juga dan banyak spot foto yang keren-keren. Saya juga sudah empat kali ke Bunkasai". Cosplay merupakan gabungan kata costume (kostum) dan play (bermain). Cosplay berarti hobi mengenakan pakaian beserta aksesoris dan rias wajah seperti tokoh-tokoh dalam anime, manga, video game, penyanyi dan film kartun. 
Berikut tabel perbandingan antara beberapa cosplay pada acara bunkassai dengan film Anime

Tabel 1. Perbandingan Cosplay Bunkassai dan Anime

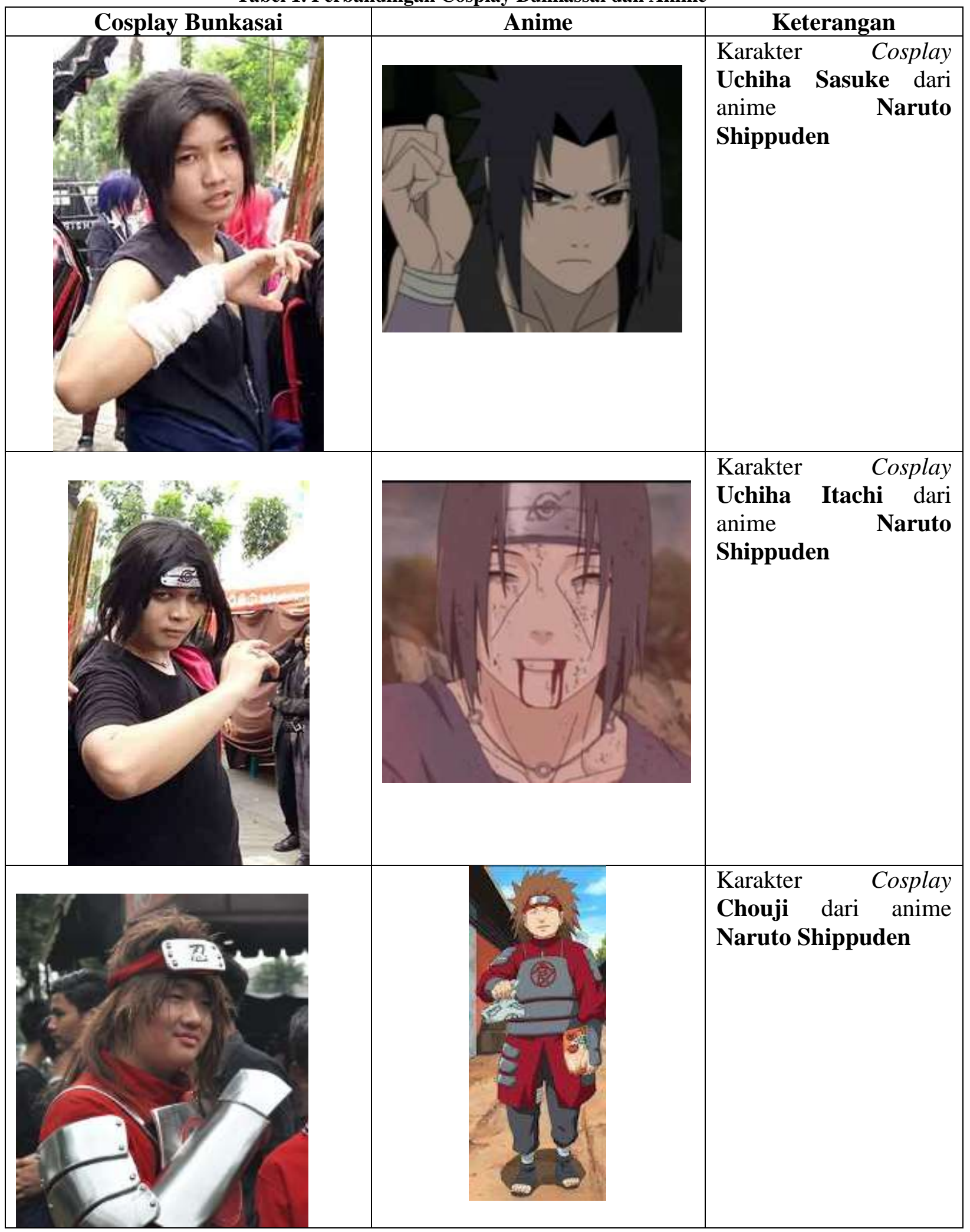




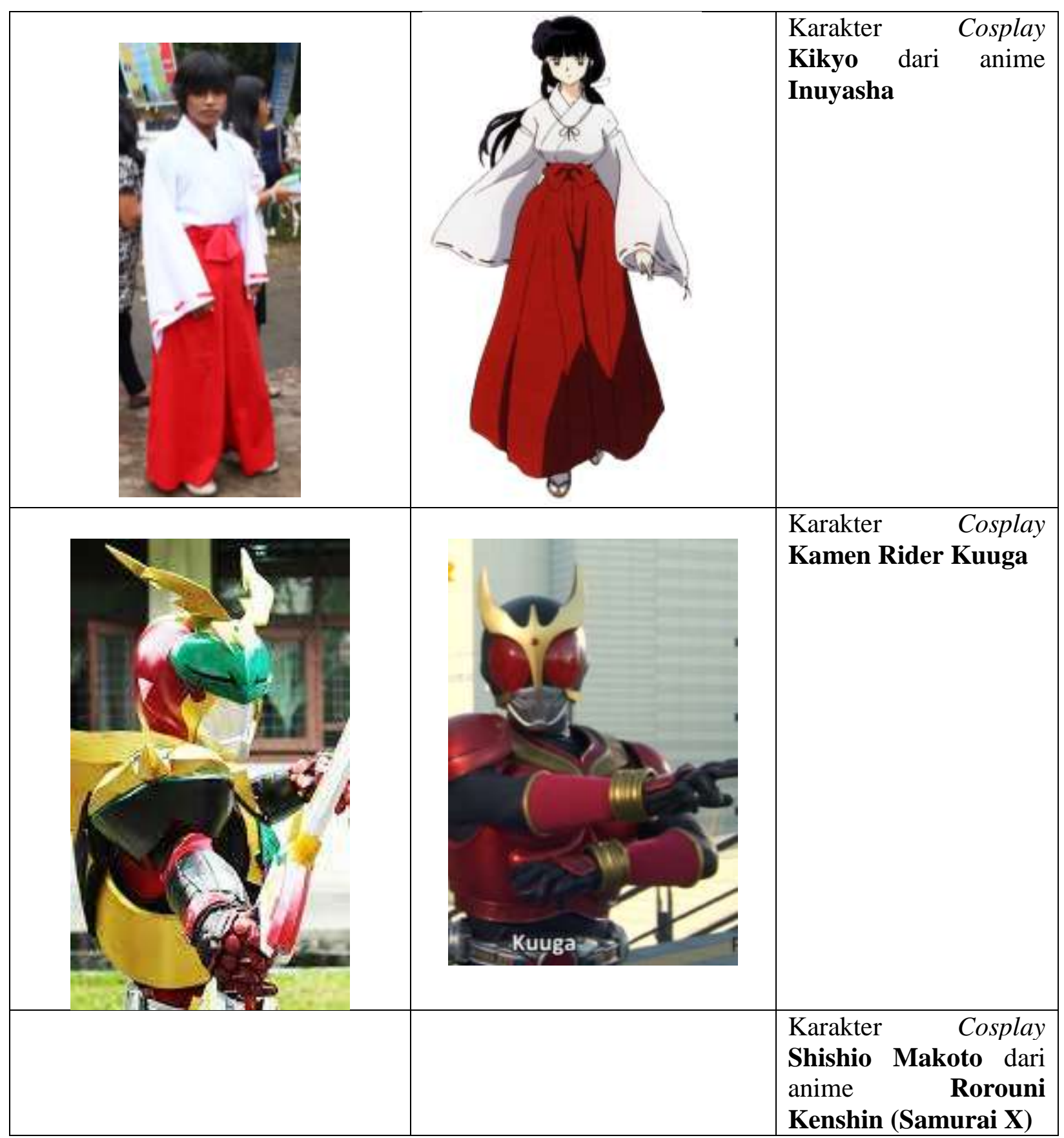




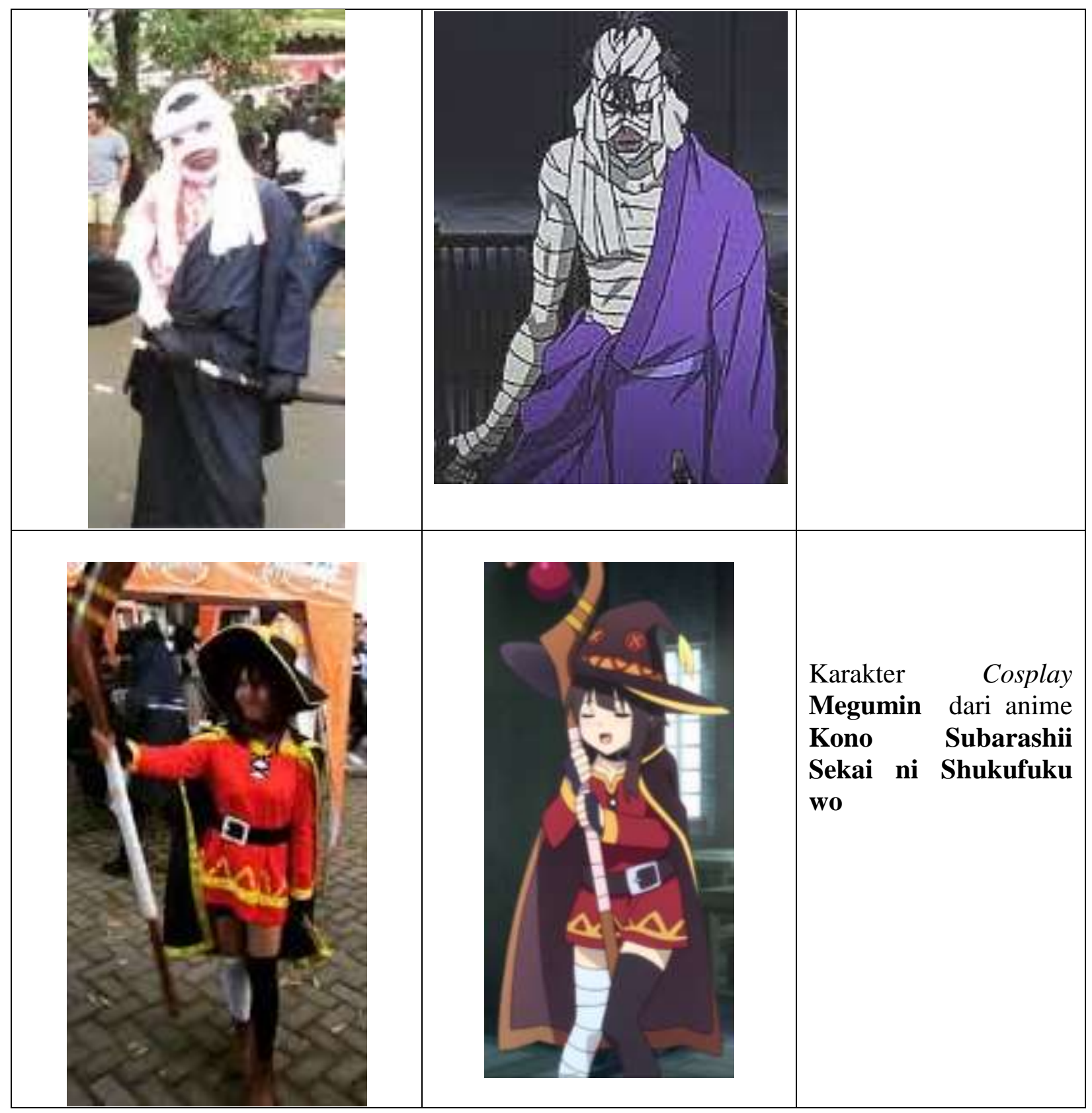




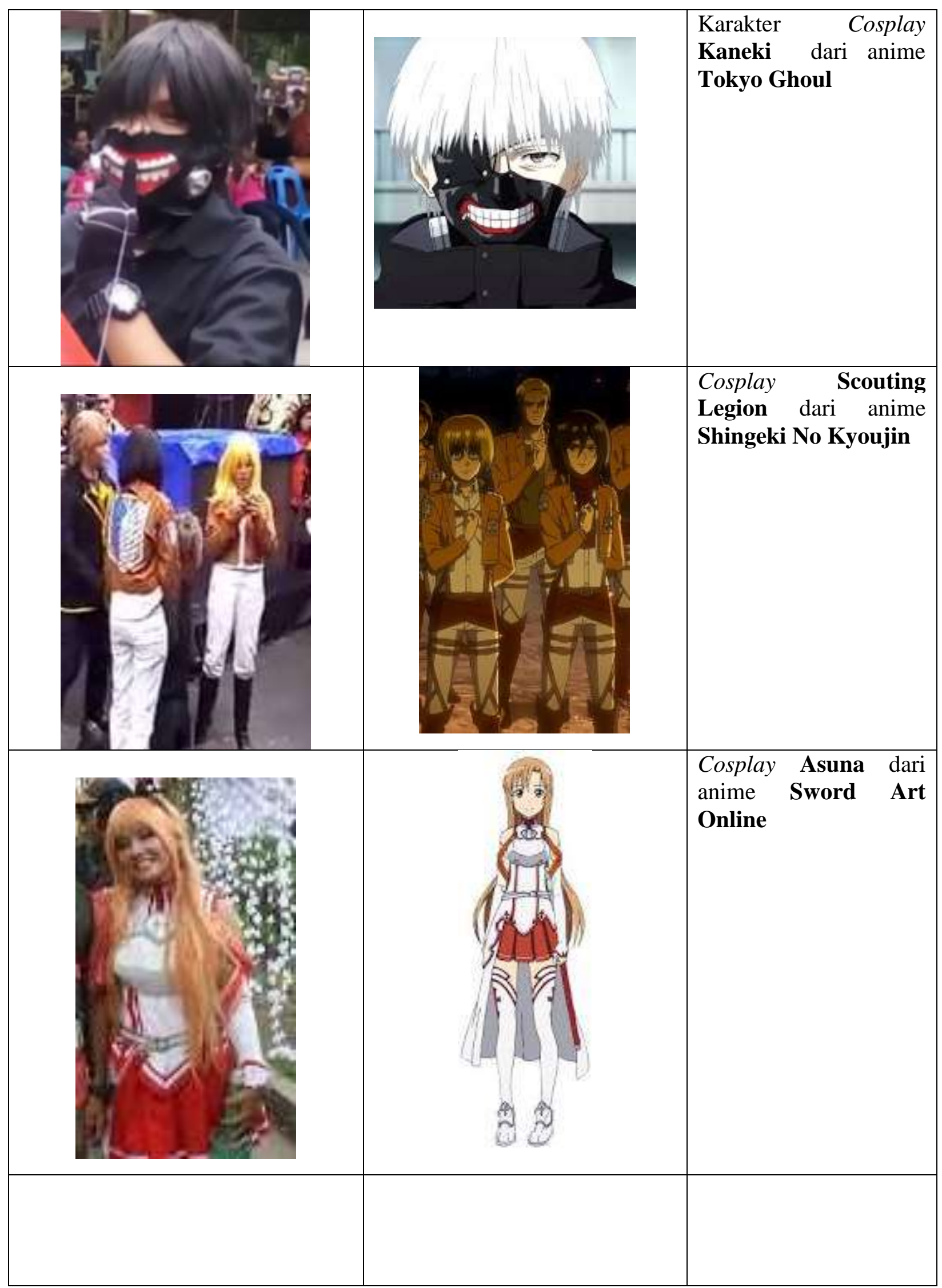




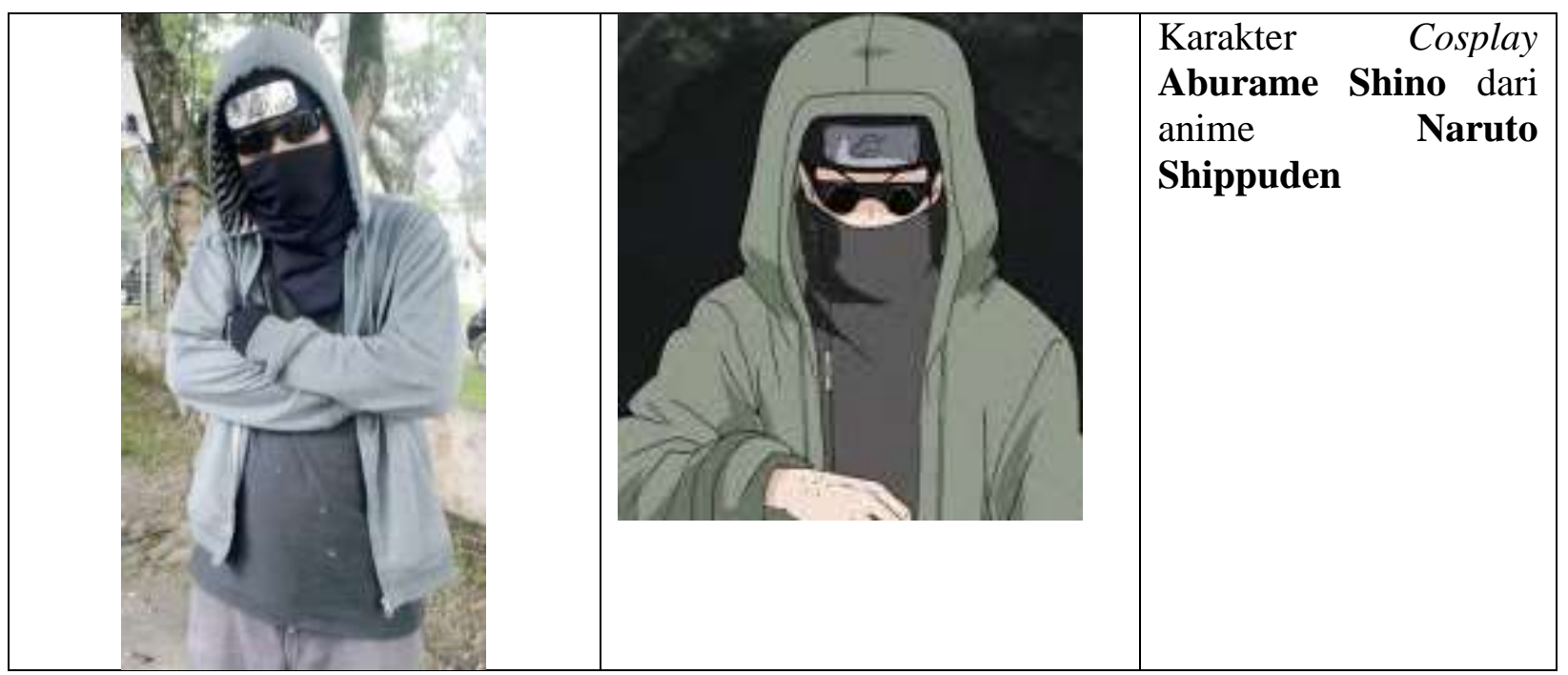

\section{KESIMPULAN}

Budaya populer yang pada akhirnya disebut sebagai budaya komoditas ini diproduksi secara besar besaran hanya didasarkan pada keuntungan ekonomi semata sehingga hal ini memberikan pengaruh buruk bagi masyarakat karena penilaian baik atau buruk bukan lagi didasarkan pada ajaran moral tetapi lebih pada kemampuan ekonomi untuk mendapatkan prestise.

Selain itu, produk produk budaya populer akan merusak budaya elite dan sistem tata krama alam kehidupan bermasyarakat. Budaya populer ini akan menciptakan khalayakkhalayak pasif karena semua kebutuhan hidup sudah disediakan. Penilaian baik buruk dan pedoman pedoman dalam hidup sudah ditentukan dan diatur oleh industri budaya.

Keragaman budaya indonesia yang menjadi kekayaan negeri ini sedikit demi sedikit telah luluh dan menghilang digantikan oleh budaya-budaya modern yang dianggap lebih maju. Budaya-budaya yang menggiring manusia pada pendangkalan makna. Industri budaya memproduksi budaya yang bersifat homogen dengan standar karakter karakter yang dianggap ideal. Karakter karakter manusia yang unik menjadi homogen sesuai standar standar yang di kontruksi oleh industri budaya. Manusia tidak lagi dapat memahami secara mendalam apa yang menimpa mereka saat ini, terutama pengaruh televisi yang dirasa membuat manusia sangat dangkal dalam memahami fenomena kehidupan.

Film Anime menjelma menjadi image yang sangat berpengaruh dalam mendoktrin masyarakat khsusnya kalangan remaja yang mengkonsumsi film tersebut. Fenomena ini memunculkan banyak istilah - istilah, event - event, serta komunitas jejepangan. Bunkasai merupakan salah satu bukti pengaruh besar dari sebuah film anime yang dimana konten dari acara tesebut di dominasi oleh film (anime) Jepang.

\section{DAFTAR PUSTAKA}

[1] Barthes, R. 1977. Image-Music-Text. London: Fontana Press

[2] Barthes, Roland. 2004. Mitologi. Yogyakarta: Kreasi Wacana 
[3] Bignell, J. 1997,. Media Semiotic: An Introduction. England: Manchester University Press.

[4] Danesi,. M. 2002. Understanding Media Semiotics. London: Arnold.

[5] Heryanto, Ariel. (2012). Budaya populer di Indonesia : Mencari Identitas Pasca-Orde Baru. Yogyakarta: Jalan Sutra.

[6] Kress, Gunther \& Theo van Leeuwen. 2006. Reading Images: The Grammar of Visual Design, Second Edition. New York: Routledge.

[7] Kress, Gunther \& Theo van Leeuwen., 2006. Reading Images: The Grammar of Visual Design, Second Edition. New York: Routledge

[8] MacWilliams, M. (2011). Japanese visual culture: explorations in the world of Manga and Anime. New York: M.E. Sharpe.

[9] Moleong, Lexy. J. 2012. Metodologi Penelitian Kualitatif. Bandung: PT. Remaja Rosdakarya.

[10] Mudjiono, Yoyon. Kajian Semiotika dalam Film. Jurnal Ilmu Komunikasi. Vol.1, No.1, April 2011. ISSN: 2088-981X

[11] Rose, G. 2007,. Visual Methodologies: An Introduction to Interpretation of Visual Materials, Second Edition. London, England: Sage Publication

[12] Storey, John, (2007). Pengantar Komprehensif Teori dan Metod Cultural Studies dan Kajian Budaya Pop. Penerbit: Jalasutra, Yogyakarta.

\section{Internet :}

[13] http://www.cakapmedan.com/artikel.php?artikel=20

[14] http://www.mediapijar.com/2018/05/kemeriahan-festival-budaya-jepang-pada-bunkasaiusu-2018/

[15] http://fib.usu.ac.id/content/index/4/id_cnt_berita_child?id=39

[16] http://bunkasaiusu.blogspot.com/2018/01/events.html 